\title{
INVESTIGACIÓN SOBRE LA APLICACIÓN DE LA ORIENTACIÓN FILOSÓFICA EN LOS CUIDADOS DE SALUD. PRIMERA PARTE
}

\section{Research on the Application of Philosophy to Health Care. FIRST PART}

\author{
FRANCISCO. E. BARRERA RODRÍGUEZ \\ Universidad de Sevilla \\ franciscobarrerarodriguez@yahoo.es
}

RECIBIDO: 21 DE OCTUBRE DE 2010

ACEPTADO: 24 DE NOVIEMBRE DE 2011

\begin{abstract}
Resumen
Este trabajo investiga las vinculaciones entre la Filosofía Aplicada y los cuidados de salud. La primera parte analiza el concepto de salud y prepara la aplicación de la Filosofía al ámbito de la salud. La segunda describe los modos en que diversos orientadores filosóficos han llevado a cabo esta labor. La tercera contendrá la propuesta del autor sobre cómo llevar la Filosofía al paciente.

Palabras clave

Filosofía Aplicada, cuidados de salud, orientación filosófica, paciente

Abstract

This work researches the links between Philosophical Practice and Health Care. The first part analyses "Health" concept and it prepares to the application of Philosophy to Health world. The second one describes how some philosophical counsellors have undertaken this work. The third one contains the author proposal about how to take philosophy to patients.
\end{abstract}

Keywords

Philosophical Practice, Health Care, Philosophical Counseling, patient

\section{Lo que se ha entendido por salud. Breve recorrido histórico}

Si preguntásemos a cualquiera qué entiende por salud, nos encontraríamos con una respuesta repetida en la que se dibujaría a ésta simplemente como ausencia de enfermedad, seguramente en la creencia mayoritaria de que la vida es una continua secuencia de padecimientos en las que se nos otorgan etapas que esbozan espejismos de tranquilidades. 
No han sido pocos los que han definido el concepto de salud o han manifestado conclusiones a cerca de este atributo, ni los que han expresado contrariedad a las mismas, en cualquier caso podríamos afirmar que no existe lengua que no recoja un vocablo similar, lo que podríamos traducir como bienestar, o disfrute de una vida agradable con necesidades básicas satisfechas y en buen estado físico, este último aspecto conectaría directamente con lo que podemos definir como "estar sano" y en consecuencia identificarlo con objeto de trabajo de la Medicina.

No muy lejos de esta idea, un grupo de expertos de la Organización Mundial de la Salud (OMS) definió la salud como "el completo estado de bienestar físico, mental y social y no sólo la ausencia de enfermedad o invalidez". En esta definición, la palabra bienestar es sinónimo de salud y por ende sería identificada con una existencia placentera en lo físico, en lo mental y en lo social. Tal vez, cabría pensar si la OMS no ha cristalizado el deseo de felicidad en una definición asequible como es la salud.

En cualquier caso, cabría reflexionar sobre la posible constatación del relativismo histórico en el que nos aparece la idea de salud, cuyo valor social, como ocurre con la enfermedad y con la muerte, se modifica en función de la época y la cultura. El psiquiatra Juan Casco Solís afirma, que una de las constantes en el momento de construir la idea de salud, parece haber consistido en proyectar la visión idealizada de la sociedad que cada época ha tenido de sí misma ${ }^{1}$.

Muy brevemente, casi de pasada no vendría mal una revisión capaz de mostrarnos el desarrollo histórico que ha presentado este concepto en distintas culturas para identificar en ellas conceptualizaciones capaces de acercarnos a la interioridad más profunda de éste término.

En el antiguo Egipto, donde se vivía pensando en la muerte, salud y enfermedad, que en este caso presentamos como antitéticos, eran manifestaciones de un drama originado por causas externas. Entre los extremos de la vida y la muerte, la salud quedaba subordinada a la interacción equilibrada de las fuerzas de la materia y el espíritu, la

\footnotetext{
${ }^{1}$ Cfr. Casco, J.: “Curar la salud” Archipiélago. Cuadernos de Crítica de la Cultura, no 25, 1996.
} 
gravedad de la enfermedad iba en directa proporción a la gravedad de la armonía desajustada.

En Mesopotamia, se mantenía la idea de que las enfermedades eran el castigo que los dioses imponían a los hombres transgresores de sus normas, en consecuencia para recuperar la salud había que buscar la armonía entre el ofensor y el ofendido. Es fácil ver estas ideas ancestrales presentes en el inconsciente colectivo. Aún hoy muchas personas consideran las enfermedades como castigo a los hombres impuesto por los dioses.

Casi todas las grandes culturas comparten la existencia de una armonía entre las sustancias que integran la materia humana. El Ying y el Yang (China), el equilibrio de fuerzas vitales (India), la equidad entre las sustancias que integran la materia humana (Cultura Helénica). Podemos por lo tanto considerar que la salud gira en torno a los conceptos de armonía, equilibrio, equidad, siendo lo opuesto lo atribuido a la enfermedad.

Desligar salud de enfermedad o, como anteriormente decíamos, presentarlos como antitéticos, ya no queda tan claro. La enfermedad es también un concepto positivo que no tiene que traducirse necesariamente por ausencia de salud o de perfección, luego cabría pensar la posibilidad de una coexistencia. En consecuencia no habría ni salud total ni enfermedad total, cabría una opción bifronte, recordemos la definición de salud de Ivan Illich cuando decía que la salud sería la capacidad que tienen los individuos para lo que le es inherente a su propia condición: nacer, crecer, afrontar cambios, envejecer, enfermar y morir.

Ese equilibrio al que nos referíamos antes de este breve lapso, es patente en el pensamiento de Aristóteles: el "justo medio" como punto de equilibrio entre las fuerzas. El mundo helénico nunca vio la salud apartada de la armonía y el propio Marco Aurelio, nos habla de una interacción armónica entre materia y espíritu con un universo rector. De aquí podríamos concluir que desde la antigüedad subyace la idea de que la salud es una condición que traduce el equilibrio dinámico entre el hombre y su ambiente, un apunte de la relación de un ajuste dinámico del organismo con el entorno.

Desaparecido el Imperio Romano, médicos árabes, persas y judíos revitalizaron los conocimientos de la medicina griega y de las figuras de 
Galeno e Hipócrates. Los médicos árabes y judíos fueron líderes en la medicina occidental hasta la fundación de la Escuela de Salerno, que vuelve a hacer suya la idea greco-latina de fomentar la salud mediante la prevención, es decir, mediante los preceptos higiénicos. En la sociedad feudal de la Edad Media repleta de epidemias, guerras, hambre y otras tragedias, la salud era una entelequia, siendo en la expansión del cristianismo, creencia de que el bienestar, la infelicidad y la enfermedad y al fin todo lo concerniente al hombre ya sólo dependían de Dios.

Paracelso, en el S. XVI, intuye nuevos horizontes para la medicina que pasan por el laboratorio alquimista, donde se mezclan entre otras cosas, astros y pensamientos escolásticos. Finalmente, sobre Hipócrates y Galeno se construye la estructura de la medicina de la Edad Moderna.

No quisiera hacer de esta brevísima revisión histórica un inútil compendio de definiciones sobre lo que a lo largo del tiempo el hombre ha entendido como salud, es por eso por lo que para finalizar este recorrido, miramos hacia ese momento en el que la noción de salud aporta un elemento de crucial importancia para la reflexión que pretendemos desarrollar, y es el considerar a la colectividad. Hasta este momento, y hablamos de primeros del S. XIX, las definiciones de salud se habían situado a nivel individual y no se había preguntado por la salud de las colectividades. Así Walter B. Cannon, inaugura un nuevo concepto denominado Homeostasis Social ${ }^{2}$, que sugiere que la salud depende del equilibrio de todos los elementos que dan cohesión a la sociedad. Aquí, aparece el Estado como tutor de sus súbditos en lo que a salud se refiere. A este respecto, no podemos olvidar los programas de promoción de salud en las conclusiones de las reuniones convocadas por la OMS, para la Promoción de la Salud en el Siglo XXI que tuvo lugar en Yakarta en $1997^{3}$ donde se dice que: "Los requisitos para la salud (de la población) son: paz, vivienda, educación, seguridad social, relaciones sociales, alimentación, ingreso económico, mayor poder de la mujer, ecosistema estable, uso de recursos sostenibles, justicia social, respeto por los derechos humanos y equidad".

\footnotetext{
${ }^{2}$ El fisiólogo W.B. Cannon de la Universidad de Harvard comenzó a apuntar esta teoría en 1920.

3 Cfr. http://www.administracionsanitaria..com/RAS_PRIMERA/05/02_documentos.pdf. (Última visita 8 septiembre de 2006)
} 


\section{La salud del Estado Terapéutico (E.T). Una construcción esquizoide}

La tutorización ejercida por el Estado y secundada por la medicina propone al individuo los caminos para alcanzar el perfecto estado de salud, ambas, sobrepasando sus funciones, se ponen en marcha para la instalación del individuo en un espacio denominado Sociedad del Bienestar con miras a una longevidad y calidad de vida que debe ser el objeto de deseo más inmediato y excitante.

En este constructo no podemos obviar que aparece un cuerpo doctrinal que bajo ningún sentido puede cuestionarse, es fe debida, dogma para el individuo de la sociedad neoliberal que debe orientar sus pasos y sobre todo su comportamiento hacia esos caminos diseñados por un Estado Terapéutico que al tiempo que diseña los mejores planes para solucionar los problemas de sus súbditos construye en un círculo irracional y esquizoide todo un sistema de enfermedades y malestares a los que acude para subsanar a posteriori con un derroche de terapias, tecnologías, quimioterapias...etc.

Esta esquizofrenia no puede develarse, no está permitido. Hay miles de intereses económicos que la respaldan y que analizaremos más adelante. Así, el ET desarrolla un circuito cerrado donde por una parte construye el malestar y por otra oferta sus soluciones.

No hay más que detenerse a reflexionar sobre cómo el Estado arroja a los individuos a un mundo de competencia exhaustiva, de trabajos inhumanos y mal remunerados, de enloquecedor consumo incontrolado, de continuo ataque al medioambiente, de actitudes que nos señalen como vencedores y líderes sobre los menos favorecidos, desecando existencias e insuflando más aire viciado a una sociedad cada vez más insolidaria donde la soledad y el desencuentro cabalgan a sus anchas, y al mismo tiempo, de forma paradójica, nos tiende la mano para ofrecernos cura y alivio a los malestares que él mismo ha provocado.

La medicina hoy, totalmente inmersa en la tela de araña del ET no es capaz de deshacerse de la política económica en la que se ha situado desvirtuando su verdadero objetivo, el de un verdadero servicio público. 
El ET pone en funcionamiento una estrategia donde la salud se presenta como una exigencia colectiva que es controlada y supervisada por sus estructuras amparándose en lo que es "científicamente recomendado".

La idea de bienestar, tan unida a la de la salud aporta al individuo hábitos de consumo y estilos de vida, la capacidad al fin de estos sujetos para satisfacer sus necesidades sin grandes dificultades para acceder a la felicidad.

Esta identificación de calidad de vida, bienestar, salud y estatus social conecta inevitablemente con la capacidad adquisitiva, con la economía, aspecto reiterado y reinante en este nuevo discurso de una medicina que se pliega no ya a las necesidades del enfermo sino a las del ET que ve en el médico el perfecto transmisor de sus proyectos normalizadores.

La medicina del siglo XXI tiene a sus espaldas la mayor de las desorientaciones desde su corta historia como disciplina científica, allá por los inicios del XIX. Nunca más que hoy habita en ella la incertidumbre y el cuestionamiento de arquetipos y paradigmas que se supusieron inamovibles. Plegada a sistemas sanitarios desequilibrados, al mercado de las grandes empresas farmacéuticas, a políticas sanitarias de conveniencia y a la esclavitud de la tecnología ve cómo se tambalea su estructura, cuando además el ET la convierte en objeto político. ${ }^{4}$

En este territorio, se plantean enormes dilemas que intentaremos recorrer en las próximas páginas y que nos van a mostrar una serie de cambios significativos en el mundo de la medicina y por ende de la enfermedad y el sufrimiento.

A los ya expresados anteriormente, se plantearán otros de no menor interés, como la supremacía de la tecnología sobre la clínica, el olvido de la medicina como arte de medios, el uso casi paranoico de las quimioterapias, la medicalización obsesiva de nuestras vidas, al punto de querer convertir en enfermedades procesos tan naturales como la gestación, el nacimiento o la muerte.

De la mano de los intereses de las industrias farmacológicas, la medicina actual activa "nuevos deseos de salud" desde los iconos de la

\footnotetext{
${ }^{4}$ Cf. Foucault, M. La vida de los hombres infames. Altamira, Buenos Aires, 1997.
} 
estética y el "sentirse bien", al tiempo que propicia una medicina que bajo el rótulo de preventiva lo único que hace es "patologizar" multitud de experiencias humanas.

La preocupación neurótica fomentada por el ET traspasa los límites de una mínima racionalidad. Fomentando, por ejemplo, desde los medios de comunicación la necesidad de “curarse” de la vejez, la obesidad, las arrugas... es también responsabilidad de ese estado tutor, conductor al fin de una sociedad-rebaño consumidora que sucumbe a la idea más narcisista y consumista de lo que identifica con la mejor de las calidades de vida.

Al fin, el individuo construye un proyecto existencial totalmente huero y desfondado, consumir es su proyecto hacia una meta imposible, la de abandonar su miserable condición de ser humano, que irreductiblemente camina hacia la muerte. Nunca podrá curarse de vivir y lo que ello supone, y en consecuencia, no podrá afrontar la realidad.

La sociedad-rebaño, en gran manera, es reconducida por estas lindes, y la medicina participa activamente en este proceso, el de generar individuos inmaduros, infantiles, perfectos consumidores que quedan desvalidos ante cualquier contratiempo, ante cualquier adversidad y en consecuencias incapaces de afrontar cualquier frustración.

\section{La salud entre la economía y la política.}

El fenómeno de la continua medicalización a la que se somete en las últimas décadas la vida de los individuos provoca que experiencias y fenómenos que pertenecían a otros campos sean reconducidos por la medicina, convirtiéndose a partir de entonces en fenómenos o experiencias médicas.

En este proceso, por lo tanto, se incorporan a esta disciplina "nuevas patologías” que obviamente encontrarán sus "terapias”, incontestables por otra parte, al ojo divino de la ciencia médica, al tiempo que se hará especial hincapié en que su "tratamiento" no puede ser abordado desde otra alternativa a la que se marginará y expulsará con efusión del “espacio oficial”. 
No podemos hablar de medicalización sin referirnos a autores como: Illich, Foucault, Navarro o Mendelsohn, pero especialmente a Ivan Illich, porque su "Némesis Médica", que por los años 70 apareció envuelta en un halo de radicalidad, hoy es perfectamente asumible y nada exagerada.

Illich plantea sin rodeos que la medicina ha rebasado los límites tolerables y que resulta patógena, que causa al fin daños clínicos muy superiores a los beneficios. Abunda el autor diciendo que ésta enmascara las condiciones políticas que minan la salud de la sociedad expropiando el poder del individuo para curarse a sí mismo y para modelar su ambiente. $^{5}$

Redundando en lo anteriormente expuesto, Illich nos habla desde su "yatrogénesis", de la continua invención de enfermedades desde los estamentos médicos y subraya la importancia que tiene las condiciones de vida y el medio para su afrontamiento más que la propia terapia.

Otro aspecto de la excesiva medicalización es, según este autor, el monopolio curador (en los límites de la imposición) de los médicos, aspecto vigente en nuestros días cuando se debate entre dos de los principios más recurrentes de la bioética: la autonomía y la beneficencia.

De suma importancia para nuestro trabajo es su denuncia de la fractura que se produce en la relación medico-paciente, en cierto ensañamiento terapéutico producido por la obsesión de aplicar el tratamiento sea cual sea el resultado, y la pérdida de decisión y autonomía frente al aparato sanitario creado por el ET, donde también hace referencia a la muerte tecnológica y sus consecuencias. ${ }^{6}$

\footnotetext{
${ }^{5}$ Cf. Illich, I. Némesis médica: la expropiación de la salud. Barral Editores, Barcelona, 1974.

${ }^{6}$ Para Illich la medicalización de la sociedad es un resultado de la superindustrialización. Illich considera inevitable que un tipo de sociedad de producción como la occidental, donde la enseñanza (tema de sumo interés para el autor) está programada, la residencia urbanizada, el tráfico motorizado, las comunicaciones canalizadas, parece evidente que la medicina deba producir salud y que el paciente sea un mero cliente de la empresa médica. Para Illich el paciente en este territorio queda reducido a un mero objeto de reparación, como la pieza de un reloj, deja de ser un sujeto, pierde su individualidad y se le secuestra del proceso no dejándole participar.

En este sentido Humberto Galimberti confluye en la misma preocupación que Illich cuando en su: Idee, il catalogo é questo, describe el paso del cuerpo del enfermo como sujeto de sesiones chamanísticas y experiencias precientíficas a convertirse en la base de la nueva realidad construida por el médico. El médico ya no ve al enfermo, sino a la enfermedad, subraya Galimberti, y en su cuerpo no lee una biografía sino una patología. El cuerpo termina reduciéndose a organismo, donde el cuerpo del enfermo carece de espacio a la enfermedad, pasando a un espacio específico, el hospital, en el que las comunidades que se crean son sólo las que imponen la taxonomía de los
} 
La continua construcción de la enfermedad es un proceso insaciable. En la actualidad no es fácil delimitar la línea que divide lo que es la enfermedad y lo que no es. Cada vez con mayor frecuencia se convoca a la enfermedad ante el menor signo que pueda provocar sospecha. Aspectos estéticos, factores de riesgo, previsiones de sufrirla en el futuro (mapa genético)...etc.

Altamente significativo resulta para ilustrar esta idea la votación propiciada en 2002 por una revista especializada.

En su mejor línea democrática el British Medical Journal auspició el pasado año una votación sobre cuáles son en nuestro entorno las principales "no enfermedades", aquellos procesos cuya inclusión en el campo de la actuación de la medicina resulta menos obvia. Como colofón de este proceso, su edición de 13 de abril de 2002 se dedicó al tema de la medicalización de la vida, con el objetivo explícito de atraer la atención sobre la tendencia en aumento a clasificar como enfermedades los problemas de la gente. Dada su capacidad de influencia, ese número del BMJ marcará con toda seguridad un hito importante en la historia del pensamiento sanitario por su contribución a crear opinión sobre un fenómeno que está afectando de manera importante la forma de vida en las sociedades del primer mundo. ${ }^{7}$

Etiquetar nuevas enfermedades conlleva obviamente a la generación de terapias que necesariamente precisarán de farmacología e instrumentación tecnológica específica, en las que las empresas del sector estarán muy atentas para ofrecer en el menor tiempo posible soluciones farmacológicas y tecnológicas que a posteriori en muchas ocasiones han demostrador ser no sólo inválidas sino perjudiciales, entre otras cosas porque han sido soluciones adoptadas con prisas, sin validación fiable, más para responder a una demanda de política sanitaria que para servir a la demanda del individuo enfermo.

Todo ello nos sitúa en las tierras movedizas de las empresas farmacéuticas, donde se justifica de una manera ultra ortodoxa la filosofía neoliberal que ensalza el libre mercado de la oferta y la demanda y en consecuencia se blindan para que se ejerza cualquier tipo de control que

órganos.

${ }^{7}$ Márquez, S. y Meneu, R. La medicalización de la vida y sus protagonistas. Bajado de http://www. revistadefilosofia. org (Último acceso 13 febrero de 2007). 
pretenda regular, a favor de los enfermos, uno de los negocios más deplorables de la economía del último siglo.

Es evidente que la producción de medicamentos por parte de las industrias farmacéuticas no parte de otro origen que el próspero negocio y no el que entendemos natural fin del bienestar de los seres humanos que habitan este deteriorado planeta.

Es por todos conocida las inversiones multimillonarias y los cientos de recursos puestos a disposición de propagandas, presiones e innumerables chantajes sobre las autoridades encargadas del control de los medicamentos. Todo es válido, el mercado así lo permite, incluso pasar por encima de las necesidades más inmediatas de millones de personas que se verán fuera, no ya de lo que entendemos en occidente por salud, sino de la mínima oportunidad para combatir cualquier mal o enfermedad perfectamente soluble con determinados medicamentos.

Los intereses de los ciudadanos se ven enfrentados con los de estas multinacionales que arrojan ganancias exorbitantes año tras año. No hay pausa en la batalla, y una clara muestra de esto es la guerra a raíz de los medicamentos genéricos y los resguardos de las patentes ${ }^{8}$. No hay opción terapéutica disponible para los más pobres, para los que nada poseen.

Es espeluznante comprobar, y éste es uno de los centenares de ejemplos de lo que referimos, el caso de los medicamentos "anti sida". Los números que ofrecen los organismos mundiales al respecto nos hablan de millones de afectados en África, Asia y América sin opción al tratamiento. No hay otros caminos para ellos que una terapia a través de medicamentos genéricos o de patente a bajos costos.

El historial de la política de guerras, presiones, chantajes, juicios y estratagemas propias de verdaderos carniceros de la humanidad (no deberíamos olvidar los seres humanos que mueren cada minuto por esta

\footnotetext{
${ }^{8}$ Un informe del Programa Conjunto de las Naciones Unidas sobre el VIH/SIDA (ONUSIDA) de Panamá, indicó que el hecho de comprometerse cada vez más a proteger a la propiedad intelectual de las industrias farmacéuticas en los países desarrollados, reduce los espacios para las competencias dando como resultados que los medicamentos se compren a precios altos y en consecuencia se registra menos accesibilidad para la población pobre. La entrada en vigor de Tratados de Libre Comercio (TLC) como el de Centroamérica, redundaría en erogaciones sanitarias más elevadas para los países en desarrollo, pues estudios efectuados en naciones que ya han adoptado estos acuerdos neoliberales indican que se han encarecido exageradamente los medicamentos para el tratamiento del VIH y otras enfermedades. Naciones Unidas (2001, junio). Periodo extraordinario de sesiones de la Asamblea General Cfr. http://www.un.org/spanish/ag/sida/. (Último acceso 4 febrero de 2007).
} 
actitud justificada del neocapitalismo que tanto celebramos en nuestras sociedades occidentales del primer mundo), está plagada de casos. Recordaremos a modo de referencias los casos de Pretoria, Italia (Veneto), Alemania o Estados Unidos, donde la presión de las corporaciones farmacéuticas terminaron en los tribunales en procesos con acusaciones de pagos ilegales, sobornos, ofrecimiento de dinero, regalos, etc.

Quizás, uno de los casos más sobrecogedores es el vivido por Pretoria hace años, cuando se realizó un juicio, en este caso promovido por nada más y nada menos que 39 compañías internacionales farmacéuticas contra el propio gobierno del país alegando que la ley sudafricana del 1997 violaba las reglas comerciales mundiales de la propiedad intelectual, al abrir vías a la importación paralela y a la producción local de sustitutos genéricos ${ }^{9}$.

No podemos más que denunciar con toda la fuerza posible el atropello que estas industrias realizan sobre poblaciones desahuciadas, sobre seres humanos que por el mero hecho de nacer en territorios no desarrollados están condenados a la miseria y el sufrimiento, a la desigualdad, al dolor y a la injusticia, en la mayoría de las ocasiones propiciados por los pobladores de ese primer mundo desarrollado, culto y neoliberal que vive a costa del sufrimiento y el olvido de los otros, los desheredados.

Una de las labores del filósofo, quizás la primera, debería ser la de sacudirse el polvo de las bibliotecas y asomarse a la realidad más inmediata. Como nos propone Susan Sontag en su obra y con su vida, y a la que arribaremos más tarde en nuestra reflexión sobre la metáfora de la enfermedad, la actitud crítica es esencial, y es necesaria una denuncia y una propuesta de reflexión por todos, cuando unos pocos viven la opulencia en detrimento de los otros.

\footnotetext{
${ }^{9}$ El caso de Pretoria, donde las compañías farmacéuticas se unen claramente contra el ciudadano para que éste no acceda a un medicamento a más bajo coste, es uno de los casos más evidente de lo que venimos contando. Como consecuencia de este proceso la ley de 1997 referida estuvo bloqueada por decisión judicial durante algunos años, tiempo en el que se llegaron a acuerdos que afortunadamente beneficiaron a la población que tuvo acceso a los medicamentos a bajo coste. En definitiva, el hilo central de la problemática que hemos referido a Pretoria nos dibuja el miedo que las compañías farmacéuticas tenían a disminuir sus entradas multimillonarias anuales si aparecían otros competidos mundiales con menos fama, aportando similares medicamentos pero a precios mucho más asequibles.
} 
No podemos pues seguir manteniendo esta situación, es necesaria la eliminación de patentes y otros monopolios para que se puedan atender los males de los más pobres. La sociedad, en su totalidad, todos sus sectores, deben propiciar este cambio. El filósofo también. Es necesario romper este proceso para que leyes y patentes no impidan la salud a los que se la hemos negado ${ }^{10}$.

Está fuera de dudas que los medicamentos pueden ser mucho más baratos. Simplemente se trataría de tener acceso a los genéricos. Un ejemplo, un tratamiento con antirretrovirales genéricos puede costar 209 dólares por año, en cambio hacerlo con medicamentos patentados nos llevaría hasta un coste aproximado de 10.000 dólares por año. Por otra parte, hay que tener en cuenta que la fabricación de genéricos fuerza a una reducción de los precios: los fármacos patentados que tienen competidores genéricos se han visto obligados a reducir en un 33\% sus precios, mientras que aquellos que no tenían competencia redujeron sólo el $2 \%$.

Actualmente, las compañías farmacéuticas tienden a restringir los fondos dedicados a I+D a favor de los productos más rentables. Según el informe del "Panos Institute" de Londres. Patent report, pills and health 11 de los 1.393 nuevos productos farmacéuticos que han salido al mercado en los últimos 25 años, sólo 13 eran para enfermedades tropicales ( $0,9 \%$ de la investigación).

Según este documento, aunque los países en desarrollo representan el 80\% de la población del planeta, para las empresas del sector sólo suponen el $21 \%$ de las ventas, en consecuencia la mayor parte de la inversión de la industria farmacéutica ha ido destinada a buscar

\footnotetext{
${ }^{10}$ De sumo interés respecto al tema de las patentes me parecen las conclusiones extraídas de las Jornadas de propiedad Intelectual de Málaga celebradas en Málaga por la Universidad Internacional de Andalucía (UNIA) en su mesa redonda sobre patentes farmacéuticas y Salud Pública, donde se ha profundizado entre otros temas por la obligación que tienen los poderes públicos de garantizar el derecho a la protección de la salud de los ciudadanos, y sobre cómo la idea de este derecho debe estar por encima de los derechos comerciales y de propiedad intelectual. Además, se ha reflexionado en este foro, que tuvo lugar el mes de marzo del pasado año 2006, sobre los medicamentos genéricos y normativas legales que pueden completar ampliamente lo expuesto al respecto. Cf. UNIA. Jornadas Críticas de Propiedad Intelectual de Málaga (2006, marzo). Mesa redonda: Patentes farmacéuticas y salud pública, [en línea]. Málaga, España. Recuperado el 21 de enero de 2007, de http://www.unia.es/artpen/ezine/ezine08_2006/frame.html.

${ }^{11}$ Cf. The Panos Institute. Patent report, pills and health, Londres. Bajado de: http://www.panos. org.uk/PDF/ reports/TRIPS_low_res.pdf. (Último acceso 9 agosto de 2006).
} 
soluciones para problemas como la calvicie o las disfunciones eréctiles, a pesar de que como todos sabemos no suponen ningún riesgo para la vida.

Algunas cifras como las que a continuación siguen, nos muestras con claridad el estado de las cosas.

- El coste de un mismo tratamiento de tuberculosis representan alrededor de 500 horas de trabajo en Tanzania, 100 en Zimbabwe, 20 en Tailandia y 1, 4 en Suiza.

- Un tercio de la población mundial no tiene acceso a fármacos esenciales. En países pobres de África y Asia afecta a la mitad de la población.

- El coste de las medicinas representa el $74 \%$ de los gastos de salud en el África subsahariana, el 25 \% en Latinoamérica y área del Caribe, y un 7,8 \% en los países desarrollados. Según la OMS, en los países desarrollados, los laboratorios farmacéuticos ingresan entre el 50 y el $60 \%$ del precio final del medicamento; en algunos países subdesarrollados más del $80 \%$ del precio que pagan los consumidores es por derechos de importación, impuestos y costes de distribución y venta.

- La OMS estima que aplicar los derechos de las patentes farmacéuticas en los países donde no se consideran puede suponer un incremento de entre el 12 y el 200\% de los precios de los fármacos en estos países.

¿Existen alternativas? Parece que sí. En cualquier caso no son ya pocas las voces que desde distintos foros y entidades piden una alternativa a esta situación. ¿Adónde queremos ir?

Por una parte, en el primer mundo la hipermedicalización no deja de etiquetar a los individuos a marcha forzada sobre su estado anormal de salud. Se devalúan las formas no médicas para afrontar dificultades y tanto sociedades como personas son cada vez más dependientes de la medicina y de los recursos sanitarios que se van implementando de una forma escalofriante. La creación de una sociedad en constante alerta médica construye vidas insanas e hipocondríacas bajo el continuo mensaje de que una sociedad medicalizada es una sociedad de mayor bienestar.

El miedo de la enfermedad se ha apoderado de una parte del mundo. El rico, donde ya nadie muere en paz, y donde se dispara el consumo de 
medicamentos para remediar algo tan irremediable como es vivir, y mientras, en la otra parte del mundo la gente sigue muriendo de Sida, infecciones y enfermedades para nosotros fácilmente resolubles.

Contra este desatino, al que todos contribuimos, nacen muchas propuestas y proyectos para cambiar las cosas, para denunciarlas, para hacerlas visible a todos en el intento de despertar en cada uno de nuestros interiores la necesidad de una respuesta al "otro". Es el caso de películas como El jardinero fiel , documentales como Sicko o libros como The truth about the drug companies: how they declive us and what to do about it de Marcia Angell o Los inventores de enfermedades. Cómo nos convierten en pacientes de Jörg Blech.$^{12}$

Pensando que las soluciones existen muchas organizaciones no gubernamentales han propuesto a la OMS en tanto que es el único organismo intergubernamental internacional legalmente establecido para gestionar la salud en el mundo que elabore una agenda de investigación prioritaria de los futuros medicamentos que no esté condicionada por criterios comerciales. Por otra, para financiar la investigación y desarrollo de fármacos necesarios para combatir enfermedades endémicas en el Tercer Mundo, el doctor James Orbinski, de Médicos sin Fronteras,

\footnotetext{
${ }^{12}$ El jardinero fiel, basada en una obra de John Le Carré y dirigida por Fernando Meirelles denuncia la corrupción de una multinacional farmacéutica en Kenia. La novela, según el autor, está basada en hechos reales acaecidos en Nigeria.

Para los inicios del verano del 2007, se espera con no poco interés, el trabajo documental del estadounidense Michael Moore (Bowling for Columbine, Fahrenheit 9/11) su nuevo documental Sicko. Este documental es un retrato del sistema de salud estadounidense, una crítica a la industria farmacéutica y un retrato de las necesidades que atraviesan los pacientes. El realizador compara el sistema sanitario privado de EEUU con el público de acceso universal existente en Canadá. Moore ha revelado a varios medios de información que el sector sanitario y farmacéutico en Estados Unidos está realmente asustado con su película hasta el punto que han tratado de paralizar el rodaje durante meses al bloquear los seguros que se necesitan para hacer la película.

El libro de Marcia Angell, ex directora de The New England jorunal of Medicine, La verdad sobre la industria farmacéutica: cómo nos engañan y qué hacer al respecto es un alegato contra la industria farmacéutica y su falta de renovación y revisa los precios y la mentira de lo novedoso de los fármacos cuando, dice, precisan de un marketing muy intenso.

En la línea similar del libro de Angell, el bioquímico y periodista alemán Jörg Blech mantiene en su libro Los inventores de enfermedades. Cómo nos convierten en pacientes, que fármacos para tratar la obesidad, la impotencia y la alopecia inundan las farmacias occidentales, mientras que en los países africanos, enfermedades como el cólera, la malaria o el dengue siguen matando a millones de personas.
} 
ha lanzado la idea de crear un impuesto sobre las ventas mundiales de la industria farmacéutica, una especie de tasa Tobin ${ }^{13}$ farmacológica .

\section{Salud, marketing y televisión. La construcción de una nueva teología}

Se pregunta Thomas Szasz en uno de sus libros más representativos, ${ }^{14}$ cómo consiguió la medicina triunfar donde fracasó la religión, para automáticamente contestarse que esto ha sido posible porque la medicina, ha modificado nuestro vocabulario y nuestras categorías conceptuales. Simultáneamente, ésta ha subvertido nuestros ideales y desplazado el poder de las instituciones dedicadas a protegernos, al de quienes nos ayudarán, en y de cualquier forma, tanto si queremos como no.

Para Szasz, esto se produce al llamar a las personas pacientes, llamando al encarcelamiento hospitalización, a la tortura terapia, llamando a los individuos que no se quejen sufrientes y a los médicos y a los profesionales de la salud mental, que infringen, en palabras del autor, su libertad y dignidad, terapeutas.

Desde esta visión, que no es precisamente muy reciente, casi treinta años distan desde que el psiquiatra húngaro puso en alerta sobre el control y la normalización desde la medicina, haciendo especial hincapié en la psiquiatría- a la mirada que hoy podemos mantener sobre la medicina, el sufrimiento, las instituciones sanitarias y lo que venimos llamando en este trabajo el ET y su intervención en la sociedad, poco o nada ha cambiado.

Szasz nos adelanta lo que hoy vivimos en torno a la experiencia del sujeto en la enfermedad, como individuo y como ser perteneciente a una comunidad que ha desarrollado unas estructuras y unos procedimientos

\footnotetext{
${ }^{13}$ Economista norteamericano, obtuvo el Premio Nobel de Economía en 1981 por su análisis de los mercados financieros y sus relaciones con las decisiones de gasto, empleo, producción y precios. En 1972 propuso que los gobiernos recaudaran una tasa sobre las operaciones con divisas, como medio para disuadir la especulación desestabilizadora. Veía esta tasa como una forma de ayudar a fomentar el libre comercio, ya que garantizaba a los países que podían abrir sus mercados sin exponerse a movimientos perjudiciales de 'dinero caliente'. Esa propuesta es la que han recogido los movimientos anti-globalización con el nombre de tasa Tobin, convirtiéndola en un símbolo de la lucha contra el libre comercio.

${ }^{14}$ Cf. Sasz, T. La teología de la medicina. (Trad. A. Escotado). Tusquets, Barcelona, 1981.
} 
dentro de ellas que son perfectamente identificables con las denunciadas por Szasz.

Nos previene el autor de esta nueva iglesia que se alza sobre el paciente y el médico, y cuya teología marca las reglas de juego (salud pública), desde donde no caben disensiones.

Szasz deja una reflexión crítica importante en torno a la construcción de esta teología que se desarrolla alrededor de la necesidad de aliviar el sufrimiento como único sentido de vida y nos advierte de los peligros de aquellos programas políticos cuya meta era el alivio más radical del sufrimiento de la sociedad, generando a la postre mucho más dolor.

La normalización de la salud desde el ET es hoy por hoy una realidad indiscutible, más subrayada incluso que cuando nuestro psiquiatra húngaro o el mismo Illich ponían el grito en el cielo para alertarnos sobre ello. Hoy la tecnología juega un papel determinante en este proceso, al punto incluso de desplazar al instrumento más preciado del orden del ET y del capital como es el médico.

Si el médico hasta ahora aparecía legitimado por la razón, la ciencia y el poder público y ejercía el sacerdocio de la salud, hoy se ve relegado a un segundo estadio. Si hasta hace poco ha jugado a favor de la medicalización y la tecnificación de todos los procesos que se construyen en la medicina hospitalaria, ahora ha cedido un poco su papel de autoridad indiscutible porque sus dos ahijadas (farmacopea y tecnología) le han sustituido en el papel principal, en el proceso del milagro de curar.

De repente, quien preparase la sintonía adecuada para desde un conjunto de símbolos y metáforas reforzar el apriete continuo de tuerca del ET sobre el ciudadano se encuentra desposeído de ese poder del sacerdocio. La bata blanca, el lenguaje encriptado ${ }^{15}$, el uso indiscriminado del título de doctor se han rendido a la tecnología. Sus enfermos acceden desde Internet al lenguaje sanitario y conocen al minuto la información que desean. Esperan más del fármaco y del equipo tecnológico más puntero que de esa figura en la que antes se depositaba la esperanza de vivir.

Lejos de abandonar su papel de mediador entre la empresa (la farmacéutica) y el cliente (el paciente), el médico sigue ejerciendo de

\footnotetext{
${ }^{15}$ Cf. Comelles, J.M. "La utopía de la atención integral en salud. Autoatención, práctica médica y asistencia primaria”. Revisiones en Salud Pública, 199, (3), pp. 169-192.
} 
cooperador del motor económico de las sociedades neoliberales y si en su trabajo en los ambulatorios ha pasado a ser poco más que un burócrata expendedor de recetas y bajas laborales, ${ }^{16}$ su trabajo en el hospital se desarrolla cada vez más en una dependencia casi total del desarrollo tecnológico.

En este punto, es muy habitual percibir el malestar de la clase médica que en diferentes foros manifiesta, de forma reiterada, pérdidas de referencias en su desempeño y se ha lanzado a una relectura de su papel en la salud del siglo XXI.

La nueva teología ya no la presiden los médicos, ellos ahora son introductores de los dos grandes astros de la medicina del siglo XXI, que obviamente vienen acompañados de todo un despliegue mediático y de marketing para una perfecta adhesión al ciudadano del estado- ganadero, que sin contemplaciones exige a su llegada a un hospital los mejores medicamentos y las pruebas radiológicas más avanzadas para descartar males mayores a su, pongamos por ejemplo, una leve contusión sin mayor trascendencia.

En todo este complejo proceso no podemos olvidar que los medios de comunicación de masas son, a continuación de los profesionales de la salud, la principal fuente de información al respecto. Es fácil sorprenderse muchas mañanas al leer titulares engañosos sobre avances y nuevos descubrimientos en patologías de gran importancia, propiciando la desorientación y creando unas expectativas imposibles de cumplir.

Para sustentar este circo todas las empresas de tecnología médica y las grandes industrias farmacéuticas se cuidan mucho de contar con gabinetes de prensa, imagen y relaciones exteriores que, con muchos medios, “provocan y dirigen la información”. El círculo se cierra.

La concepción de lo noticiable está asociada a la novedad, lo inusual, lo improbable o lo deseado. De ahí la sobreabundancia de noticias sobre pretendidos descubrimientos revolucionarios, soluciones mágicas y terribles plagas de dudosa base científica.

El principal problema de una lectura acrítica de los medios estriba en que favorecen en la población la confirmación de expectativas que están por encima de la realidad, contribuyendo de modo importante a generar la creencia en una

\footnotetext{
${ }^{16}$ Cf. Canals, J y Romaní Oriol. "Médicos, medicina y medicinas: del sacerdocio al marketing”. Archipiélago. Cuadernos de Crítica de la Cultura, 1996, (25), p. 55.
} 
inexistente medicina omnimoda. La sensación de que la medicina es una ciencia exacta es, en buena parte, creada y alimentada por los medios, siendo cada vez más exigible que éstos asuman e incorporen a sus contenidos términos como "incertidumbre" o "limitaciones".

Se han documentado casos en los que el tratamiento de los problemas en los medios de comunicación está lleno de contradicciones, subrayándose aspectos negativos e ignorando otros relevantes. Como ejemplo, un estudio que analizó la información sobre la menopausia en la prensa, encontraba que se trivializaban los aspectos relacionados con promover estilos de vida saludables, y por el contrario, se enfocaba el tema como una experiencia negativa, una enfermedad y una etapa que necesitaba tratamiento médico. En muchas ocasiones, son los médicos ejerciendo de columnistas, o sus sociedades a través de campañas de prensa, quienes promueven la medicalización e incluso el uso de intervenciones cuyos efectos adversos superan los posibles beneficios. En los últimos años el cribado del cáncer de próstata ha aportado un buen número de ejemplos poco edificantes. ${ }^{17}$

En este punto, la medicina, mitificada, referida como panacea para cualquier mal, incluida la vejez, encuentra en sus sacerdotes profundos cuestionamientos sobre el papel a desempeñar, a pesar de no ser estos los mejores tiempos para reflexiones críticas. Por eso, me parece de particular interés el trabajo dirigido por el Dr. Daniel Callahan en el "Hastings Center" de Nueva York a propósito de los fines y prioridades de la medicina de cara a este nuevo siglo, porque es un ejercicio que nos muestra de forma clarificadora en qué lugar estamos y hacia dónde caminamos en el campo de la medicina.

\section{Los fines de la medicina en los inicios del siglo XXI}

El trabajo citado nos sirve de guía para tomar el pulso a esa crisis a la que nos referíamos anteriormente, parte de uno de los más prestigiosos centros de investigación en bioética, el "Hastings Center" de Nueva York y en resumen podemos decir que consistió en el análisis por un tiempo de cuatro años por parte de un grupo de estudiosos internacionales que representaban a catorce países del mundo de los fines de la medicina en el marco de sus posibilidades y problemas contemporáneos.

${ }^{17}$ Márquez, S. y Meneu, R, op., cit., (25), p.55. 
Los catorce países representados crearon cada uno su equipo de trabajo para analizar esta problemática no a nivel internacional sino en su contexto nacional formando equipos multidisciplinares donde estuvieron presentes: médicos, biólogos, juristas, filósofos, teólogos, administración y gestores de la política sanitaria y salud pública.

Los países participantes fueron: Alemania, Chile, China, Dinamarca, España, Estados Unidos, Holanda, Hungría, Indonesia, Italia, Reino Unido, República Checa, República Eslovaca y Suecia.

El espíritu de este trabajo dirigido por el filósofo americano Daniel Callahan queda patente en su prólogo cuando hace una crítica directa a la falta de reflexión sobre los fines de la medicina que ha caracterizado la medicina de los últimos años segura de sus paradigmas y firme en su pedestal.

Sin embargo, una de las grandes satisfacciones de nuestra labor a lo largo de estos cuatro años ha consistido en convencer a la mayoría de los escépticos de que una falta de reflexión en los fines de la medicina podría acabar socavando las bases de las reformas prácticas que necesitan, y que la formulación de preguntas básicas no es simplemente "teórica", sino enormemente práctica si tenemos en cuenta sus implicaciones. ${ }^{18}$

Compartimos con Victoria Camps que lo novedoso del documento es la reformulación de las prioridades de la medicina de nuestro siglo, y el situar a un mismo nivel el curar y el cuidar.

La novedad fundamental del texto que traducimos es haber podido formular nuevas prioridades en la práctica de la medicina. Los fines de la medicina, a finales del siglo XX, deben ser algo más que la curación de la enfermedad y el alargamiento de la vida. Han de poner un énfasis especial en aspectos como la prevención de las enfermedades, la paliación del dolor y el sufrimiento, han de situar al mismo nivel el curar y el cuidar, y advertir contra la tentación de prolongar la vida indebidamente. ${ }^{19}$

Es de subrayar del informe algunas matizaciones que nos conectan con nuestro trabajo. Los responsables del informe apuestan por un cambio en

\footnotetext{
${ }^{18}$ Cf. Varios Autores. Cuadernos de la Fundació Víctor Grífols i Lucas. Los fines de la medicina. Coord. Daniel Callahan. Fundació Víctor Grífols i Lucas, Barcelona, 2004.

${ }^{19}$ Cuadernos de la Fundació Víctor Grífols i Lucas, op.,cit., (11), p. 6. Cursivas del autor.
} 
la formación de los nuevos médicos, un cambio que pasa por una nueva mirada hacia el enfermo que se encamina hacia el morir y por una formación complementaria entre la que se incluyen las humanidades.

A los estudiantes de medicina se les debería enseñar que la muerte es algo inevitable y que no siempre les será posible curar al enfermo. Además, deben aprender a enfrentarse a los problemas que suponen las enfermedades crónicas. Las nuevas generaciones de médicos deberían recibir formación en economía, humanidades y organización de la asistencia sanitaria, para así poder hacer frente a las realidades económicas de los sistemas sanitarios actuales ${ }^{20}$.

Otra de las conclusiones de este informe se acerca a la reflexión sobre el peligro que corre la medicina en su acompañamiento por la revolución biomédica y por las innovaciones tecnológicas. De nuevo se pone sobre aviso de los posibles efectos indeseables de una medicina obsesionada con curar y de la necesidad de equilibrar y racionalizar el gasto en sanidad para hacerlo llegar a todos.

La revolución biomédica y las innovaciones tecnológicas que la han seguido suponen un verdadero hito de la historia de la humanidad merced a sus efectos positivos en la salud de la población mundial. No obstante, los avances de la medicina moderna son un arma de doble filo, pues la prolongación de la vida a menudo acarrea el coste de un mayor sufrimiento, más enfermedades y unos gastos económicos superiores. El equilibrio entre las ventajas y las desventajas de la tecnología médica avanzada es un tema que está cobrando una mayor importancia entre los responsables políticos tanto en los países en vías de desarrollo como en los industrializados.

En su afán por encontrar un presupuesto equilibrado, los entes públicos de los países ricos y pobres se ven obligados a tratar la medicina como uno de los bienes que exige la población, en competencia con los demás por unos recursos escasos. $^{21}$

Existe igualmente en el informe una llamada de atención a la intromisión de la medicina en la dirección de los individuos y en la definición de su bienestar, algo cada vez más patente en esta sociedad neoliberal en la que el cuidado de la salud se ha tornado en el cuidado del cuerpo como icono de calidad de vida y donde aparecen introducidos en mensajes con

\footnotetext{
${ }^{20}$ Ibid., p. 77.

${ }^{21}$ Ibid., p. 76.
} 
enormes cargas de control sobre los miembros del estado-ganadero pautas "saludables" para una vida mejor.

Los usos de las técnicas y el conocimiento médico son muchos; la mayoría buenos, pero en ocasiones extremadamente perversos. Entre los usos inaceptables se encuentra el empleo de información sobre salud pública para justificar la coerción antidemocrática de grandes grupos de personas para que cambien sus comportamientos "insanos". En el extremo opuesto, un fin de la medicina no puede consistir en el bienestar absoluto del individuo, más allá de su buen estado de salud. Tampoco corresponde a la medicina definir lo que es el bien general para la sociedad. ${ }^{22}$

Concluye este trabajo con una afirmación tajante a propósito de las interpretaciones que se hacen actualmente de los fines de la medicina, al afirmar que los dejan expuestos a abusos y usos incorrectos, subrayando la propuesta de que la medicina de hoy y la del futuro deberán aspirar a la moderación y a la prudencia, a poder ser para todos, es decir, asequible y económicamente sostenible, justa y equitativa y de respeto hacia las opciones y la dignidad de las personas.

\section{Dos miradas sobre el sufrimiento: Schopenhauer y Frankl}

Muy brevemente, vamos a esbozar el sufrimiento en dos autores que han desarrollado su pensamiento en torno a la vivencia del sufrimiento en el hombre, autores que han puesto especial interés en profundizar sobre la experiencia de éste y derrumba en muchos con facilidad la existencia del ser humano.

Nuestra mirada será breve por cuestiones obvias; necesitaríamos centenares de páginas para apenas abordar las aportaciones de estos autores al tema, y otras tantas para analizar lo que han supuesto estas reflexiones como aportaciones en el campo de la filosofía y la logoterapia.

Intentaré, consciente de la dificultad que conlleva, trazar al menos unas líneas generales que puedan ubicarnos en la importancia de estas reflexiones, sobre todo en lo que tienen que ver con el tema que

${ }^{22}$ Ibid., p. 77. 
investigamos, y sobre todo en lo que nos puedan clarificar de cara a la propuesta que se quiere sustentar en este trabajo de investigación, de afrontamiento del sufrimiento desde la propia filosofía, y más concretamente desde ese espacio emergente llamado OrFi.

Schopenhauer y Frankl. Tanto uno como el otro son indispensables para la propuesta de aplicación de OrFi que nos interesa, y para cualquier propuesta no grupal. El primero porque desbroza, a mi entender, toda la maleza que no nos deja ver la tierra miserable sobre la que nos sustentamos, el segundo, porque nos avisa y nos enseña sobre el sentido de vida, su construcción y sus posibilidades ante el destino inevitable del hombre, ofreciéndonos en su logoterapia un camino para asumir la responsabilidad de vivir con el mejor de los sentidos existenciales.

Parafraseando a Foerster, cuando nos decía que nadie debería ocuparse del psicoanálisis sin antes haber estudiado a fondo la obra de Schopenhauer, yo diría que nadie que pretenda adentrarse en los territorios de la OrFi puede desentenderse de las miradas de Schopenhauer y de V. Frankl.

Recalcar igualmente que la parada en Schopenhauer nos trasladará inevitablemente a Nietzsche y a Freud, por lo que completaremos el ciclo a propósito del sufrimiento en estos autores.

Partiendo de que la mirada de Schopenhauer no concibe una metafísica que califique o considere el mal y el sufrimiento como algo negativo, nos lleva directamente hacia su concepto de voluntad como la esencia del mundo.

La voluntad es un esfuerzo infinito, algo que a pesar del esfuerzo no alcanzará nunca el objetivo. Para él lo que llamamos felicidad o goce no es más que una parada en nuestro desear, en nuestro querer irrefrenable. Así, el deseo, como expresión de la necesidad y del sentimiento de privación, es una forma de dolor.

En este punto, podríamos definir la felicidad como esa liberación del dolor, el trascender en consecuencia la necesidad, pero ¿Es positiva? Schopenhauer piensa que no, es negativa porque no tarda en transformarse en tedio, con lo que el mecanismo se reactiva de nuevo, se pone de nuevo marcha a la caza de otro nuevo deseo. Ésta es la cadena del mal. La vida al fin se convierte en un péndulo que va del deseo al hastío. 
De acuerdo con ello, la felicidad siempre se halla en el futuro, o también en el pasado, mientras que el presente se asemeja a una pequeña y oscura nube que el viento empuja sobre la superficie expuesta al sol: delante y detrás de dicha nube todo es luminoso, mientras que sólo ella misma proyecta continuamente una sombra. En consecuencia el presente siempre resulta insatisfactorio, pero el futuro es incierto y el pasado irrevocable. ${ }^{23}$

Este posicionamiento nos lleva a asumir que el presente es un momento sin esperanzas, nunca podemos vivirlo, aprehenderlo, anda en medio del dolor de la voluntad de vivir y del aburrimiento.

Lo que Locke atisbaba más allá de los sentidos y nunca pudo decir y que kant le llamó cosa en sí, en Schopenhauer es una voluntad de vivir, como la propia sustancia del mundo.

Esta tendencia, que constituye el núcleo y el "en sí" de cada cosa, la venimos identificando con aquello que se manifiesta en nosotros del modo más claro bajo la luz de la plena conciencia y se llama voluntad. Su represión mediante un obstáculo, que se alza entre ella y su objetivo provisional, la damos en llamar sufrimiento y, por el contrario, la consecución del objetivo recibe el nombre de satisfacción, bienestar o dicha. Estas denominaciones pueden transferirse también a los fenómenos del mundo inconsciente, los cuales son más débiles según el grado, pero idénticos conforme la esencia. ${ }^{24}$

Esta sustancia alcanza en el hombre el culmen, el punto más elevado, y se muestra como un impulso ciego e irracional de vivir, de perpetuar, de querer continuamente más y más.

El propio hecho de existir es una tragedia para nuestro filósofo, por lo tanto no ve fuera de lugar que dado que existir es un dolor completo pensemos que lo mejor de todo sea la brevedad de la existencia. Este impulso de saltar de deseo en deseo hay que detenerlo para poder vivir, porque hay que subrayar que Schopenhauer no se plantea una huida ascética del mundo, quiere enfrentar la vida y para ello recurre desde dos perspectivas claramente presentes en su obra. Un doble diálogo; el que mantiene con el estoicismo y con el hinduismo.

\footnotetext{
${ }^{23}$ Schopenhauer, A.: El mundo como voluntad y representación. Fondo de Cultura Económica, 2 vols. Madrid, 2003. Vol. 2, p. 555.

${ }^{24}$ Schopenhauer, A.: op., cit., Vol.1, p. 405.
} 
En este sentido, hay que tener presente que Schopenhauer es el primer filósofo europeo que integra elementos del pensamiento hinduista en el núcleo de sus concepciones. El interés por este pensamiento parte de su encuentro en 1813 con el orientalista Friedrich Mayer.

Así, la negación de la voluntad de vivir deriva por una parte hacia la liberación hinduista del "nirvana" y de otra parte al "ethos" de la renuncia al deseo y lo que comporta de ilusión del pensamiento estoico.

La "esencia enferma" del mundo nos lleva a un enfrentamiento directo con Leibniz, que en contraposición hablaba de este mundo como el mejor de los posibles. En este mundo enfermo viven los hombres acabados, y aquí me gustaría reseñar la referencia que hace el filósofo a propósito de lo que denomina "compañero de sufrimiento" y que esgrime el autor en torno a la actitud vital hacia el otro, algo que nos lleva en la memoria al Canto XXIV de "La Iliada" en la actitud de Aquiles ante el dolor de Príamo. ${ }^{25}$

Es necesario salir del remolino doloroso que nos impone la volunta de vivir. Nos habla Schopenhauer de que gracias a la conmiseración, el hombre deja de hacer diferenciaciones egoístas entre él mismo y los demás.

Pero ahora, con respecto a la paradoja mencionada hace un momento, ha de recordarse que anteriormente hemos encontrado al sufrimiento como algo consustancial e inseparable del conjunto de la vida y que vimos cómo todo deseo produce sufrimiento a partir de una necesidad, de una carencia, que por ello toda satisfacción sólo es un dolor eludido y no conlleva una dicha positiva, que las alegrías mienten a los deseos haciéndose pasar por un bien positivo, pero en verdad sólo son de naturaleza negativa y el final de un mal. Lo que hacen la bondad, el amor, y la magnanimidad por los otros es tan sólo mitigar su dolor y, por consiguiente, lo que puede mover a las buenas acciones y a las obras del amor es el conocimiento del sufrimiento ajeno, comprensible inmediatamente a partir del propio y equiparado a éste. ${ }^{26}$

\footnotetext{
${ }^{25}$ En este pasaje el héroe troyano Héctor le arrebata a Aquiles lo que más quiere, su amigo Patroclo. Aquiles jura venganza y mata a Héctor, dejando el cadáver de este en un patio para que sea devorado por los perros al amanecer. Pero en la noche Aquiles recibe la visita del rey de Troya, Príamo, padre de Héctor que viene a pedirle humildemente poder llevarse el cadáver de su hijo para poder enterrarlo con los honores debidos. En este momento la rabia de Aquiles se disipa al observar el aspecto triste y noble del viejo rey de Troya y apiadándose de él le entrega a su hijo.

${ }^{26}$ Schopenhauer, A. op.,cit., vol.2, p. 476.
} 
Para salir de las aguas revueltas, hay que habitar un estado de "renunciamiento voluntario", de resignación, de tranquilidad verdadera. Consciente de que son pocos los que tienen esta disposición de imitar al asceta en el alejamiento del impulso del deseo y en devolver bien por mal sin ostentaciones nos marca este camino para podernos alejar del círculo vicioso de la voluntad.

Como alternativa válida para la salvación de la voluntad, nos acerca hacia la contemplación de lo bello, porque para el filósofo quien contempla algo bello lo admira pero no con la pretensión de lo observado para sí. Pero esto es salida para pocos, confiesa, y para estos pocos, escasa duración, corto aislamiento del mundo que se mueve continuamente hacia la muerte, hacia el sufrimiento, hacia la lucha continua con el destino de existir.

Resumiendo, Schopenhauer nos presenta un hombre contingente, carente porque desea, y en ese círculo de dolor cuando satisface el deseo arriba al hastío y al aburrimiento. Vivir es querer y desear es sufrimiento, en consecuencia vivir es sufrir.

\begin{abstract}
Ahuyentar, huir, temer desgracias, apetecer goces, todo es igual. La preocupación por la voluntad, siempre exigente, llena y mueve sin descanso a la conciencia. Y así, el sujeto de la volición se encuentra siempre atado a la rueda giratoria de Ixión, está echando siempre agua en el tonel de las Danaides, es el Tántalo eternamente hambriento. $^{27}$
\end{abstract}

Este autor no pasa evidentemente inadvertido a Freud, ni al joven Nietzsche $^{28}$, que asume en su El nacimiento de la tragedia los

\footnotetext{
${ }^{27}$ Mann, T.: Schopenhauer, Nietzsche, Freud. Alianza, Madrid, 2000, p.35.

${ }^{28}$ La postura de Nietzsche, nos lleva a un sufrimiento dador de sentido. El planteamiento es afirmar la vida no desde el gozo y el placer sino desde el sufrimiento, espacio donde se hace el héroe, el ser superior, cincelado por las dificultades que le dotan de capacidad para dominar sobre los otros. Nietzsche plantea un rechazo total a la moral y a la religión que propone una huida del sufrimiento. Nos lleva el filósofo alemán al mundo griego y desde lo apolíneo y lo dionisiaco, haciendo una interpretación muy particular, nos dice que ante el horror de existir, expresado en lo dionisiaco, donde aparece el ser primigenio en la contradicción y el eterno sufrimiento, el griego tuvo que construir el mundo apolíneo, lleno de templanza y belleza. Así la existencia sólo puede ser justificada desde la Estética. Es el paliativo para afrontar el destino de saber que todo lo que surge debe estar preparado para la muerte. Hay que mirar de cara para crecer como el héroe, y rechazar esa moral cristiana que habla de la compasión. Frente a lo que Nietzsche define como "ideas modernas" que junto a la ética tradicional pretenden eliminar el sufrimiento, el filósofo propone un "cultivo, crianza o disciplina” de este sufrimiento para la mejoría del hombre, por lo que no hay lugar alguno para la
} 
argumentos de Schopenhauer sobre el “principio de individuación” y el "velo de Maya”, también llega al psiquiatra austriaco V. Frankl cuando dota al dolor, y en este caso lo identifica con sufrimiento, de una naturaleza positiva, clarificadora, como algo que al fin nos pone en guardia y nos hace conscientes de la situación, de ahí su reiterado enfrentamiento con los sistemas metafísicos que explican el mal como algo negativo.

Pues si de algo tomamos nota, es inevitablemente cuando, por haberse interpuesto algún obstáculo, las cosas no se conforman con ella. En cambio, todo cuanto se opone, obstruye o estorba a la voluntad, y por tanto todo lo desagradable y doloroso, es al punto, inmediata e inequívocamente, sentido por nosotros. Así como no sentimos la salud de todo nuestro cuerpo, sino sólo el diminuto lugar donde aprieta el zapato, así también desviamos nuestra atención de todos aquellos de nuestros asuntos que marchan francamente bien, para concentrarla tan sólo en cualquier insignificante bagatela que nos produce irritación. ${ }^{29}$

compasión. El sufrimiento es por lo tanto portador de un aprendizaje que hace crecer al hombre, es la mayor afirmación de vida. [Crf. El origen de la tragedia. Espasa-Calpe. Colección Austral, Madrid, 2000; Más allá del bien y del mal. Alianza, Madrid, 1997 y Carrillo, Alberto J.L.: Dolor y sufrimiento en Nietzsche o la crianza del héroe. Bajado de. http://www.elementos. buap.mx/num46/htm/25.htm. (Último acceso 2 de febrero de 2006)].

${ }^{29}$ Schopenhauer, A. Sobre el dolor del mundo, el suicidio y la voluntad de vivir. Tecnos, Madrid, 2004, p. 18. 


\section{Enlazando con la visión del sufrimiento en Freud $^{30}$ no quisiera reiterar la anticipación de los escritos de Schopenhauer en algunas de las más representativas teorías de éste. Los escritos de Schopenhauer sobre la}

\footnotetext{
${ }^{30}$ Freud nos señala tres fuentes de donde procede el sufrimiento del ser humano. Una de ellas, por la que al hombre se le hace tan difícil ser feliz tiene directa relación con nuestra condición de seres finitos. El ser contingentes. Una segunda fuente de sufrimiento para el ser humano, que está relacionada muy estrechamente con la primera tiene que ver con la incapacidad para dominar la Naturaleza. Nuestro organismo, como parte de ella, está sometido a sus leyes por lo que es preciso reconocer lo limitado de nuestra capacidad frente a tal gigante Tenemos un cuerpo condicionado por la decadencia y su aniquilación.

La última fuente de sufrimiento es de origen social, proveniente de la insuficiencia de métodos para regular nuestras relaciones sociales. Una sociedad construye una serie de actitudes y valores culturales en la creencia de que son útiles en tanto estén puestas para su servicio, esto es, para su protección y conservación. El propio cuerpo, el mundo exterior y las relaciones con los semejantes son las tres ventanas por las que se cuela el sufrimiento en la casa del hombre freudiano.

Para Freud el ser humano ha pagado caro la evolución. La moneda que ha tenido que entregar ha sido su vida instintiva. Hay que construir reglas para regular esas relaciones, normas para la mutua protección. Se trataba en definitiva de ir construyendo un orden social con tabúes. De otra manera, se trata de sacrificar impulsos en beneficio del grupo, del bien común.

Esta renuncia a la satisfacción de los propios impulsos pasará la cuenta al individuo y provocará pulsiones que buscarán otros caminos de satisfacción. Aquí está, además de la contingencia y el mundo exterior, una de las causas de mayor sufrimiento del ser humano. El control organizado por esa cultura se mueve en dos aspectos muy determinados del ser humano: su sexualidad y su agresividad. Así la cultura como origen del malestar del hombre recibe una respuesta de éste. Una actitud, una confrontación, una manera de actuar de cada uno de nosotros frente a esa prohibición que nos es transmitida en forma de norma.

Esta insatisfacción, que de nuevo nos lleva hasta Schopenhauer, señala una carencia, una privación que hace que el ser humano se convierta en un ser sufriente. En consecuencia su actitud será la de buscar una satisfacción de esa falta, de lo que está careciendo como lucha despiadada. Dolor y placer, deseo y ausencia. Vuelta al círculo.

La represión es una barrera de choque, una pantalla contra lo pulsional, cuando ésta falla el inconsciente se manifiesta desde diferentes formas, sin que el sujeto pueda encontrarles sentido; fuera de él, extrañas, ajenas.

Llegamos al síntoma, que es una escritura del sufrimiento, un mensaje en una botella, una petición de saber qué sucede. El sufrimiento aparece en el individuo desde cualquiera de sus manifestaciones que la clínica atiende: histerias, angustias, melancolías, depresiones, psicosis...

La construcción del psicoanálisis quiere provocar en el sujeto una mirada de sus carencias, de sus deseos, esos que no son conscientes. Las trampas que le provocaron ese sufrimiento residen ahí.

El trabajo contra el sufrimiento en este espacio dista enormemente del que planteamos en el principio de este trabajo cuando señalábamos que la OrFi se movería desde un acompañamiento develador de lo desconocido. Aquí, el psicoanálisis ofrece un proceso develador de ese síntoma que señala el malestar y que hay que interpretar. El sujeto necesita esa interpretación, el psicoanalista debe descifrar y así lo hará con sus herramientas, donde llegará al campo de lo inconsciente, allí donde habita ese dolor, no para extirparlo sino para hacerlo presente, desocultarlo, y una vez desnudo y mostrado al sujeto, iniciar el camino hacia la cura. (Cfr. Psicología de las masas; Más allá del principio de placer; El porvenir de una ilusión. Alianza, Madrid, 1978 y El malestar en la cultura. Alianza, Madrid, 1970).
} 
locura nos presentan ya la teoría de la represión de Freud y su primera teoría sobre la etiología de las neurosis. La obra de Schopenhauer contiene aspectos de la teoría de libre asociación (hilo de la memoria), además de aportar la mayor parte de la teoría freudiana de la sexualidad.

No son pocos los autores que han referido este paralelismo que nos parece importante destacar. Es el caso de Bischler, Proctor-Greg o Ellenberger.

No quisiera abandonar el trabajo de Schopenhauer en su reflexión sobre el sufrimiento sin vincularlo con el expuesto en el parágrafo siguiente y que hace referencia al sufrimiento que genera la explotación en el trabajo. Su preocupación por este tema expuesta en el final de su volumen 2 de El mundo como voluntad y representación se actualiza en pleno siglo XXI en el esquema de las sociedades tardocapitalistas, verdaderas fuentes generadoras de sufrimiento. ${ }^{31}$

Si la medicina y la psicología comparten como finalidad la extirpación del sufrimiento, el borrarlo del mapa del hombre a toda costa, filosofía y psicoanálisis apuestan por atravesarlo, convencidas ambas de que es un elemento propio y singular de la vida.

No quiero reiterar lo ya expuesto sobre Logoterapia en el capítulo cuatro de este trabajo, donde presentábamos las coincidencias y la conexión de la OrFi con esta disciplina, al punto de compartir, en nuestra propuesta, una serie de herramientas de gran valor para el trabajo que igualmente se defiende en esta investigación.

Toca en este apartado detenernos un poco más a propósito de la mirada que hace la logoterapia al sufrimiento, y no sólo nos interesa la narración de los lugares en el hombre donde la descubre, sino fundamentalmente qué hacer con ella.

No podemos perder nunca de vista al hablar de la logoterapia las circunstancias que rodearon la vida de su creador, Viktor E. Frankl, algo esencial si, como es el caso, hablamos del sufrimiento del hombre. Este psiquiatra austriaco vivió casi en simultáneo el internamiento en los campos de concentración nazis de Auschwitz y Türkheim y la pérdida de sus seres queridos, situaciones que le dotan de toda la autoridad moral

\footnotetext{
${ }^{31}$ Schopenhauer, A. (2003). El mundo como voluntad y representación. Trad. Roberto. R. Aramayo, Fondo de Cultura Económica, 2 vols. Madrid 2003 Fondo de Cultura Económica, Vol.2, p.560.
} 
para hablarnos, explicarnos y enseñarnos el sufrimiento físico, psíquico y espiritual de un ser humano.

La tragedia de Frankl, no lleva, contra lo que se puede pensar, a un rechazo frontal contra todo aquello que se identifica con el sufrimiento, obviando, como nos recuerda el psiquiatra vienés, los significados y sentidos que habitan en él.

Frankl está convencido que es esa búsqueda de sentido la que sustenta toda vida, y el hombre está en disposición de sufrir siempre que este sufrimiento le señale un camino, una razón, un sentido.

Uno de los postulados básicos de la logoterapia estriba en que el interés principal del hombre no es encontrar el placer, o evitar el dolor, sino encontrarle un sentido a la vida, razón por la cual el hombre está dispuesto incluso a sufrir a condición de que ese sufrimiento tenga un sentido. ${ }^{32}$

Frankl nos propone en su filosofía un añadido a la propuesta kantiana del atreverse a pensar, nos propone que nos atrevamos a sufrir. El "homo sapiens" debe ser "homo patiens" porque esa actitud le predispone a convertir el sufrimiento en algo que puede trascendernos, dotarnos de más disposición hacia un verdadero aprendizaje de valores humanos. Vivir no es sólo producir, es sufrir y con ello trascender. La construcción del sentido se hace más poderosa, si atravesamos el sufrimiento hasta empaparnos de él.

Y el sentido no lo inventamos, como nos dice Sartre, el sentido lo descubrimos, y cuando nos enfrentamos a lo largo de nuestra vida a él para justificarla, para sostenerla, para no resbalar a un desfondamiento existencial, es cuando descubrimos qué queremos construir en nuestro tiempo de forma que nuestra vida se acerque a eso que tímidamente llamamos felicidad.

El enfoque de la logoterapia rebasa ese mecanismo que automáticamente identifica el sufrimiento con algo patológico. La pasión de muchos terapeutas por arrancar esa posible angustia fruto de esos planteamientos existenciales, nada tienen que ver con la posibilidad que ofrece la logoterapia para de esa crisis existencial, de ese sufrimiento, elevar un sentido bien construido y fuerte para vivir de acuerdo con uno

\footnotetext{
${ }^{32}$ Frankl, V. E.: El hombre en busca de sentido. Herder, Barcelona, 1987. Pág. 111.
} 
mismo. Son necesarios los escalofríos del asomarse a la vida. Es básico atravesar la angustia para construir con fortaleza.

Análogamente, el sufrimiento no es siempre un fenómeno patológico; más que un síntoma neurótico, el sufrimiento puede muy bien ser un logro humano, sobre todo cuando nace de la frustración existencial. Yo niego categóricamente que la búsqueda de un sentido para la propia existencia, o incluso la duda de que exista, proceda siempre de una enfermedad o sea resultado de ella. La frustración existencial no es en sí misma ni patológica ni patógena. El interés del hombre, incluso su desesperación por lo que la vida tenga de valiosa es una angustia espiritual, pero no es en modo alguno una enfermedad mental. Muy bien pudiera acaecer que al interpretar la primera como si fuera la segunda, el especialista se vea inducido a enterrar la desesperación existencial de su paciente bajo un cúmulo de drogas tranquilizantes. Su deber consiste, en cambio, en conducir a ese paciente a través de su crisis existencial de crecimiento y desarrollo. ${ }^{33}$

El planteamiento de Frankl pasa por tanto en una travesía enriquecedora por ese sufrimiento, que será capaz de cincelar el verdadero armazón de nuestro sentido. Frankl nos propone una aceptación, no una huida, y aquí, han sido muchos los que han identificado este posicionamiento con una actitud de religiosidad que, particularmente, creo que no se puede sostener. Frankl nos habla de una aceptación como conocimiento más allá de cada ser humano, como refuerzo para releernos en nuestro existir, y al mismo tiempo como aprendizaje indispensable para reconocer el sufrimiento en los otros. La propuesta de Frankl no es una aceptación del sufrimiento por el sufrimiento, nadie asume o nadie debería asumir voluntariamente el dolor o sufrimiento que es posible evitar. ${ }^{34}$

La actitud de un enfrentamiento directo con el sufrimiento deja sin sentido la revelación que este ha de proporcionarnos en cada momento de nuestra vida, como parte indisoluble de nuestra condición de seres humanos. La realidad nos demanda un esfuerzo, un sufrimiento, una lucha por la vida y en este sentido la línea que señala debe atravesar la dificultad. Las sociedades postmodernas han desarrollado frente a esta realidad tipo de disfraces para extraer de las vidas de cada uno de nosotros el mínimo atisbo del sufrir, con un resultado que arroja vidas desequilibradas y vacías que crecen en la frivolidad de los placeres

\footnotetext{
${ }^{33}$ Ibid., p. 103.

${ }^{34}$ Cfr. Frankl, V. E. La voluntad de sentido. Herder, Barcelona, 1983, p. 23.
} 
inmediatos y de una felicidad construida en el consumo. Es la orgía de la inconsciencia, el lugar donde vive el miedo más inmenso. El de asumir y dar sentido a lo que verdaderamente somos.

Frankl hace una llamada para que no se abandone el desafío de vivir, como verdadera actitud para llenar de sentido esa vida irrepetible y diferente de todos y cada uno de nosotros.

Hay situaciones en las que a uno se le priva de la oportunidad de ejecutar su propio trabajo y de disfrutar de la vida, pero lo que nunca podrá desecharse es la inevitabilidad del sufrimiento. Al aceptar el reto de sufrir valientemente, la vida tiene hasta el último momento un sentido y lo conserva hasta el fin, literalmente hablando. En otras palabras, el sentido de la vida es de tipo incondicional, ya que comprende incluso el sentido del posible sufrimiento. ${ }^{35}$

En la línea de las psicologías humanistas, Frankl es particularmente rígido en su llamamiento a los terapeutas a que desarrollen un verdadero acercamiento al paciente, a que miren al sufrimiento no como algo que hará que esa persona de difumine, sino como una realidad que aportará sentido. Avisa el psiquiatra vienés de la necesidad de no confundir al paciente con un dato clínico, sino que robándole la expresión a Kierkegaard, quiere que éstos vean en el ser humano que tienen frente a sí, al hombre concreto de carne y hueso que nos demanda la compasión y la comprensión. Para ello, el terapeuta debe estar dispuesto y preparado al abordaje del plano espiritual de la persona, único espacio donde puede cobrar sentido el sufrimiento. ${ }^{36}$

El logoterapeuta asume de alguna manera todas esas actitudes por las que hemos venido caminando en este trabajo. Amistad, acompañamiento, intercambio, escucha activa... debe ir mucho más allá de la normalización que propone en el malestar el psicólogo o de la maniobra psicoanalítica que pretende la ruptura del conflicto. El logoterapeuta viaja en compañía de esa persona que ha venido a pedirle ayuda. Es un camino para ambos.

Esa aceptación del sufrimiento tiene mucho que ver con la disposición o talante para enfrentarse al dolor de la enfermedad. La

\footnotetext{
${ }^{35}$ Frankl, V. E.: El hombre en busca de sentido. Herder, Barcelona, 1987, p. 112.

${ }^{36}$ Cfr. Frankl, V. E.: La idea psicológica del hombre. Rialp, Madrid, 2003.
} 
manera de asumir ese sufrimiento nos dará muchas claves del sentido. Frankl lo hace transparente cuando dice:

Lo que importa es cómo se soporta el destino cuando ya no se tiene poder para evitarlo. Dicho de otra forma: cuando ya no existe ninguna posibilidad de cambiar el destino, entonces es necesario salir al encuentro de ese destino con la actitud acertada. ${ }^{37}$

\section{El sufrimiento en la sociedad contemporánea.}

El sufrimiento impregna nuestras vidas desde principio a fin. No es muy audaz reconocer que nos acompaña recordándonos nuestra precariedad, nuestra miseria más absoluta, nuestros continuos límites convirtiéndose en la máxima expresión del drama de vivir.

El sufrimiento en nuestra sociedad neoliberal, donde el capitalismo domestica cualquier sistema ideológico, incluso aquellos que nacieron con el único fin de aniquilarlo, es objeto de ocultación y su distribución ha sido regulada por una sociedad rendida a la desigualdad propiciada por la oferta y la demanda.

No podemos, si queremos fotografiar en tiempo real al sufrimiento, obviar sus dos dimensiones, esto es, la individual y la colectiva, y su inserción en determinadas culturas que explican y normalizan este sufrimiento a la colectividad, y que en consecuencia marcará una serie de espacios, ritos y comportamientos que formarán parte de su transmisión del individuo a la colectividad y del individuo al otro.

El sufrimiento, el dolor que lo provoca es sin duda una experiencia individual, pero siempre el sujeto ha tenido la necesidad de comunicarlo al grupo, es en este momento donde nos vamos a detener primero para analizar cómo se comunica hoy el dolor, las diferencias con otras épocas y culturas y las consecuencias de ello.

El sufrimiento es una experiencia que se construye desde la cultura, donde se canaliza desde determinadas pautas, ritos, expresiones. En consecuencia, la forma de comunicar el dolor y el sufrimiento van determinadas necesariamente por la cultura de la sociedad donde se manifieste, con lo que, como apuntábamos anteriormente, el sufrimiento

${ }^{37}$ Frankl, V. E.: Ante el vacío existencial. Herder, Barcelona, 1990, p. 94. 
se somete a una norma. Hay una forma de expresar el sufrimiento que es la que la sociedad del momento ha validado para que sus miembros intercambien sus experiencias y reflexiones sobre el sufrimiento.

Desde que se construyen estos parámetros, el sufrimiento de los individuos se "medirá" de acuerdo a esta escala construida culturalmente, independientemente de que se obvie la norma.

En este punto, nos podríamos plantear muchas otras cuestiones que tal vez no son el objeto de nuestro interés especifico, si bien, no me resisto a dejarlas anotadas porque señalan de forma directa muchos tics mecánicos a la hora de mirar en "el otro" su sufrimiento. Y me refiero, esencialmente, a los consabidos: "es normal”, "es lo habitual en estos casos"...etc. Hay un dolor, en este caso un sufrimiento para cada situación, un grado de expresión que no debe ser rebasado ni minimizado, unas actitudes que no se pueden reproducir ante el grupo y otras que sí, con lo que en consecuencia el sufrimiento está, en su transmisión al grupo, totalmente mediatizado. El individuo queda por tanto desposeído de esa terapia esencial que implica transmitir "su sufrimiento" a la comunidad en la mayor libertad y como mejor sea capaz de expresarlo.

¿Pero cómo lo interpreta “el otro”? Si se ha construido un lenguaje oficial del sufrimiento, difícilmente se podrá admitir otro, otra forma de decir del sufriente que trasciende los protocolos culturales de su comunidad y vacía ante el grupo su sufrimiento con la urgencia del consuelo, sin la norma o la gramática establecida.

Otra anotación. Esta normalización del dolor justifica padecimientos y situaciones de desigualdad que dan a los poderes establecidos anchas calzadas para avanzar a toda velocidad con una lógica de la normalidad sobre la carne del ser humano.

Construido el "manual oficial del sufrimiento" se abre la veda para la justificación ruin del poder establecido que hace "natural” el sufrimiento, y lo peor, llega a apuntar a los individuos a los que debe tocarles.

Clases sociales, ideología, grupos de riesgo, enfermos no catalogados...todo va a determinar el "reparto del sufrimiento":

La institucionalización de la distribución social del dolor se acoge a criterios diferenciadores como el sexo, la edad o la posición que la persona ocupa en relación al trabajo. Pero no son los únicos criterios utilizados. No es indiferente, por ejemplo, el hecho de pertenecer a una familia u otra, o mantener una opción 
sexual o de vida distinta a la impuesta por la mayoría social. Todas estas variables y muchas otras condicionan socialmente la vivencia del dolor. Y la condicionan tanto al cargar dolor sobre las personas en función de estas variables, como al orientar la forma de afrontar estas experiencias. ${ }^{38}$

Enfermedades crónicas donde el dolor acecha y el derrumbe existencial es habitual como la fibromialgia demuestran lo expuesto anteriormente. La medicina actual no ha definido aún los parámetros para esta enfermedad, y el estado-ganadero, ve en ella, como en otros males donde la ciencia no ha podido aún contrastar la realidad de la enfermedad con pruebas científicas de la mano de la tecnología más sofisticada, una posible puerta para que sus protegidos se pierdan del resto del grupo bien apacentado. En el servicio que presta la medicina científica, que ejerce de burócrata del ET en enfermedades como ésta, se la deja bajo la sospecha, o bien, se la diluye en el pozo sin fondo de los malestares caprichosos de la sociedad del primer mundo. Como un mal de melancolía en pleno siglo XXI.

Que la vida de todos no tiene valor es una afirmación carente de novedad, pero es que cuando reflexionamos sobre el sufrimiento esta apreciación se acentúa a puntos insospechados. Ya lo veíamos la cantidad de variables que jugaban a favor o en contra de más o menos sufrimiento para la vida de un ser humano.

No todos los seres humanos tienen las mismas oportunidades para tratar sus enfermedades y su dolor. Un enfermo oncológico en Mozambique o Angola no tendrá las oportunidades de otro que viva en Alemania o en España. Como no tendrán las mismas oportunidades los niños de una comunidad de Nigeria ante el SIDA que los del primer mundo.

Para todo esto, hay sutiles construcciones del poder económico que hacen que el ser humano forme parte de un nivel u otro en función del lugar de nacimiento y de sus recursos económicos. La vida de millones de personas, el sufrimiento y la desesperación de decenas de generaciones viven en el banquete de la desigualdad y en el mordisco continuo de las grandes industrias farmacéuticas que desgarran con la voracidad de una alimaña el valor y la dignidad del ser humano en nombre de los mejores

\footnotetext{
${ }^{38}$ Madrid, A. La cultura contemporánea del sufrimiento. El vuelo de Ícaro, 2-3, 2002, p. 224.
} 
beneficios económicos. El mito de las patentes farmacológicas irrumpe en las vidas de los desheredados para recordarles que el sufrimiento es, en el reparto del mundo, más suyo que nuestro. Por derecho propio, por nacer en otro lugar, por tener otro color, otra piel, por ser mujer... por ser pobre.

Esta situación nos recuerda aquella pintada en los muros de un famoso y céntrico hospital oncológico parisino que decía: "El bienestar de algunos se nutre del sufrimiento de otros".

La vivencia del sufrimiento en los inicios del siglo XXI está marcada por diversos aspectos, pero sobre todo por la ocultación de éste, por la obsesión de esconder todo aquello que tiene que ver con la parte más desprotegida del ser humano, por eso hoy el sufrimiento se banaliza, por eso se intenta conjurar de una y mil maneras, la más insistente aquella que nos muestra el dolor desde fuera, desde los medios, desde las series televisivas, donde nos aparecen "los otros", con "sus sufrimientos", dejándonos a nosotros como meros espectadores alejados de la realidad y en mera actitud aséptica frente a algo que no será para nosotros. El mando de la televisión nos protege.

Nada es real, nada nos aleja tanto del sufrimiento del otro, nada nos introduce más en la artificialidad.

Las imágenes ofrecidas por la televisión carecen de "magnitud real”. Este hecho centra la paradoja del espectáculo mediático: acerca los acontecimientos en tanto que imágenes pero al mismo tiempo los aleja en tanto que experiencias reales.

La inclusión del sufrimiento en el espectáculo responde, en parte (no hay que olvidar que la saturación de impulsos emotivos del espectador), a un intento de preservación y autopreservación del espectador ante el sufrimiento que le rodea. Según esto, mediante la espectacularización del sufrimiento se intenta conjurar la realidad del sufrimiento, sin conseguirlo.

El espectáculo mediático favorece que el espectador confunda el hecho con su imagen. La imagen y los criterios de selección y clasificación de los que deriva se convierten una vez recibidos en nuevos criterios de clasificación y percepción del entorno cultural, político y económico de la persona. ${ }^{39}$

Este espectáculo mediático al que se refiere el autor nos lleva y conecta directamente con otro de los aspectos de referencia del sufrimiento en el siglo XXI, la medicalización del dolor. Ante cualquier dolor físico o

\footnotetext{
${ }^{39}$ Madrid, A.: op.,cit., 227. (Cursivas del autor).
} 
psíquico acudiremos al médico que es el encargado de señalar su normalidad o anormalidad. El sufriente llega al médico en multitud de ocasiones preguntando por las razones de su dolor, sin encontrar las respuestas demandadas. Como nos recuerda Illich, la civilización médica tiende a identificar y convertir el dolor con un problema técnico, dejando atrás el significado personal e intrínseco de ese sufrimiento. La experiencia del dolor y del sufrimiento fuera del marco científico y tecnológico parece no existir. ${ }^{40}$

En esta obsesión por retirar, anular, extirpar el sufrimiento que tiene la medicina, queda insoluble el necesario enfrentamiento de la realidad del sufrir. Los individuos, especialmente de esta sociedad, han olvidado la aceptación de su condición de seres sufrientes, y olvidar esto es poco menos que cerrar los ojos ante la inevitable tarea de un mirar consciente hacia la realidad más insobornable del ser humano, la que habla de su finitud, de su sufrimiento, del dolor de vivir.

Afrontar en soledad el dolor, por esa obsesión de desdibujar lo social y lo grupal en el individuo acarrea grandes cargas de sufrimientos en el campo de la salud, especialmente en el campo en el que investigamos y que desarrollamos más adelante cuando nos preguntamos por las necesidades espirituales y filosóficas de los enfermos de cuidados paliativos.

La medicina del siglo XXI, como vimos anteriormente, debe marcarse otros fines para poner en la misma línea de referencia y de atención el curar y el cuidar. No todo puede ser arrancado, extirpado, anulado. No hay medicamentos ni tecnología para multitud de sufrimientos que atrapan al ser humano. No podemos arrancarnos el evidente destino del sufrimiento, el hecho de morir.

Estamos en la era de la indiferencia, es decir, si la vida estorba, se arranca, y como no podemos hacer lo mismo con la muerte, la borramos psicológicamente de los temas a tratar. No es la autodestrucción lo que late aquí, sino una enfermedad de la mayoría: la canalización de la existencia y el hastío del ser humano, que oscilan entre la teatralidad de los medios de comunicación y una apatía generalizada por la tibieza, el escepticismo y la ambigüedad. ${ }^{41}$

\footnotetext{
${ }^{40}$ Illich, I.: op.,cit., 119.

${ }^{41}$ Rojas, E.: El hombre Light. Una vida sin valores. Temas de hoy, Madrid, 1992, p. 85.
} 
Privatizar el dolor, el sufrimiento, minusvalorar el de los otros, comerciar con el dolor de los demás en los programas televisivos y convertir sus vidas en un espectáculo forma parte de este campo yermo y despoblado de la realidad del ser humano de principios del XXI. La experiencia del sufrimiento ya no puede ser reconocida en el grupo. Se han disuelto los beneficios de la comunidad.

Es fácil observar hoy las dificultades existentes entre los individuos para transmitir su experiencia del sufrimiento. Lo decíamos antes en nuestro trabajo, enmudecemos ante el sufrimiento de los demás, no sabemos qué hacer, huimos, cerramos los ojos, lo disfrazamos, corremos un velo para tamizar las garras del dolor que inevitablemente darán con nosotros.

Susan Sontag nos recuerda que la muerte ha quedado desposeída de su sentido, que ya carece de significado en nuestras vidas. La sociedad ha construido mitos y fantasmas en torno a ella. Sontag denuncia la estigmatización de algunas enfermedades y cómo se construye en torno a ellas un motivo de vergüenza, de lastre, un castigo individual o colectivo que hay que ocultar y esconder, que hay que nombrar con metáforas.

Con la clarividencia a la que nos tiene acostumbrados, Sontag hace un llamamiento a favor de la dignidad del ser humano y hacia la responsabilidad que todos tenemos, estemos sanos o enfermos, respecto a las enfermedades y las punitivas fantasías que generan. ${ }^{42}$

En realidad, la intelectual norteamericana demanda una actitud crítica y social ante el arrinconamiento al que la sociedad neoliberal del siglo XXI somete a los sufrientes, elementos que han de ser aislados y desposeídos, ahora estigmatizados, de su propio grupo.

La muerte tecnológica del siglo XXI es una prueba irrefutable de lo expuesto hasta ahora, aquí el sufrimiento crece como una inmensa sombra hasta cubrir todo el proceso que la comporta.

El final de la vida, acompañado de rutinas inamovibles en los hospitales, desintegra totalmente al muriente, y le desposee sin miramientos de su entorno y de su familia. El aislamiento, y la soledad a la que se le castiga es un añadido brutal aumentado por la ausencia de

\footnotetext{
${ }^{42}$ Cf. Sontag, S.: La enfermedad y sus metáforas; el sida y sus metáforas. Taurus. Madrid, 1988.
} 
referencias emotivas, producto de esa obsesión de alejar a los vivos de los que van a morir o están muriendo.

En estas circunstancias, la soledad del muriente tiene pocas alternativas, y ninguna opción a que miembros del grupo puedan compartir su sufrimiento y acompañarle. Se anula toda posibilidad de compasión.

Conscientes de esta situación en los últimos años han surgido numerosos grupos de acompañamiento al duelo y grupos que han propiciado la muerte en casa como alternativas a luna muerte en soledad y despersonalizada, donde el Leviatán hospitalario devora cualquier señal de identidad del que se dispone a la muerte. ${ }^{43}$

No quisiera terminar este apartado sin hacer, aunque sea de forma breve, una referencia a otro de los sufrimientos más representativos de nuestra contemporaneidad, el producido por los deseos de consumir. Las sociedades neoliberales se caracterizan por propiciar continuamente el deseo de poseer, de tener, de ser referido por lo que se tiene. La imposibilidad, obvia por otra parte, de no poder satisfacer estos deseos multiplicados por una sociedad despiadada, arroja a la sociedad de forma constante miles y millones de almas frustradas, vacías y sometidas al sufrimiento del deseo insatisfecho.

El consumo ha sido presentado como bien, como felicidad, como camino para conseguir todo, incluso el alejamiento del propio sufrimiento. La trampa de la sociedad neocapitalista es el mejor trampolín para la desesperación de ríos de vidas que se sienten vacíos e incompletos, y sobre todo incapaces de responder a la llamada de la selva consumista que le demanda cada vez más rápido un consumo nuevo, un nuevo deseo que mañana, tal vez, será innecesario.

\footnotetext{
${ }^{43}$ En la actualidad, decenas de grupos de apoyos funcionan en nuestro país en un intento de retomar la muerte doméstica. Estos grupos, unos desde importantes asociaciones de enfermos crónicos y otros desde organizaciones no gubernamentales, trabajan con voluntarios con personal cualificado y en células multidisciplinares ofreciendo apoyo médico, psicológico, espiritual y administrativos a familias que deciden que su ser querido muera en casa. Existen numerosas peticiones desde estas organizaciones a las autoridades sanitarias para que implementen sus inversiones en equipos de atención domiciliaria que hagan posible con mayor facilidad esta demanda de muchas familias.
} 